\title{
Impacted Mandibular Permanent Incisors Associated With a Supernumerary Tooth: A Case Report
}

Fatih Ozan ${ }^{a}$

Isa Karab

Sinan Ayc

\section{ABSTRACT}

In this report, a rare case of impacted mandibular permanent incisors and supernumerary tooth associated with cystic degeneration and its treatment are described. (Eur J Dent 2009;3:324-328)

Key words: Impacted teeth; Mandibular incisors; Supernumerary teeth.

\section{INTRODUCTION}

Impacted tooth refers to situation which is fail to erupt in to the mouth normal time of eruption and appears to be originating a mechanical blocking. The main causal factors are local llack of space, ectopic positions of teeth, supernumerary teeth etc). Systemic and genetic disorders may include failure of eruption and retarded eruption as additional symptoms (cleidocranial dysplasia, osteopetrosis etc.).' Inherited retarded eruption where the delayed eruption is the only detectable

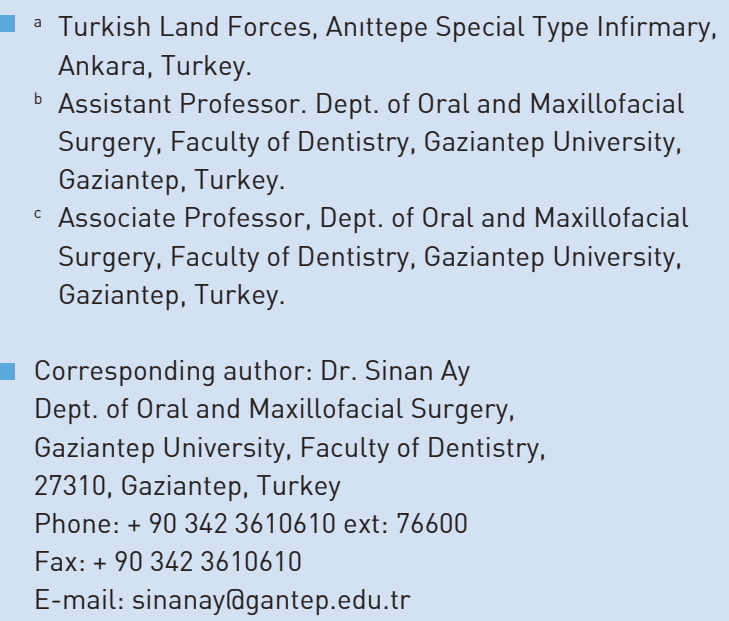

a Turkish Land Forces, Anıttepe Special Type Infirmary, Ankara, Turkey.

b Assistant Professor. Dept. of Oral and Maxillofacial Surgery, Faculty of Dentistry, Gaziantep University, Gaziantep, Turkey.

c Associate Professor, Dept. of Oral and Maxillofacial Surgery, Faculty of Dentistry, Gaziantep University, Gaziantep, Turkey.

- Corresponding author: Dr. Sinan Ay Dept. of Oral and Maxillofacial Surgery, Gaziantep University, Faculty of Dentistry, 27310, Gaziantep, Turkey Phone: +903423610610 ext: 76600

Fax: + 903423610610

E-mail: sinanaydagantep.edu.tr

manifestation of the inheritance has been reported. ${ }^{2}$

Impaction of teeth is a common event that most frequently affects the mandibular third molars and maxillary cuspids. Less commonly, premolars, mandibular cuspids, and second molars are involved. It is rare to see impactions of incisors and first molars. Impaction occurs because of obstruction from crowding or from some other physical barrier. It may occasionally be due to an abnormal eruption path, presumably because of unusual orientation of the tooth germ. ${ }^{3}$

This case report presents a rarely seen mandibular impaction of permanent incisors and a supernumerary tooth associated with cystic degeneration, and treatment alternatives are also discussed.

\section{CASE REPORT}

A 39 year-old man was referred to our clinic with complaining of pain, swelling, and discomfort of a removable partial denture (RPD). He had been wearing the RPD for 15 years. The patient had become aware of a hard whitish mass on the labial 
aspect of the alveolar ridge of the mandibular incisor region.

There was no relevant medical history. On examination, swelling in the mandibular anterior labial region along with a partly erupted tooth-like substance with normal tooth color was detected (Figure 1). On probing, lesion exhibited pocketing to a depth of about $10 \mathrm{~mm}$. Regional lymph nodes were not affected.

Radiographs showed the presence of impacted teeth on the both anterior aspect of the mandible, and a mesiodens at the anterior maxilla (Figure 2). One of the teeth was displaced horizontally, and others were vertically impacted. Physical examination revealed no anomalies or skeletal abnormalities.

Under local anesthesia the impacted teeth were removed. A supernumerary tooth was located in the most inferior position of the left anterior aspect of the mandible. The teeth were all incisors and one supernumerary tooth, but was not the right canine (Figure 3). Bone resorption had occurred around the unerupted teeth.

Soft tissue remnants associated with impacted teeth were histopathologically examined. Microscopic examination of the surgical specimen showed a cystic degeneration. The patient has shown no clinical or radiographic evidence of recurrent cystic degeneration during 2 years of follow-up and showed uneventfully healing.

\section{DISCUSSION}

Impaction defines a tooth that cannot or will not erupt into its normal functional position. ${ }^{4}$ The time interval between the exfoliation of a deciduous tooth and the eruption of its permanent suc-

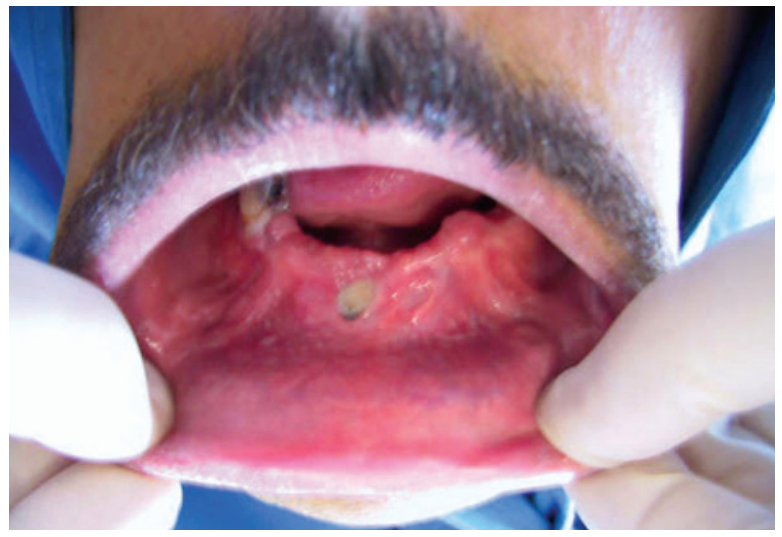

Figure 1. Intraoral view of the case. cessor is predictable; however, the delay in this process, mainly between homologous teeth, may be related to a disorder known as dental retention. ${ }^{5}$ Tooth impaction can be originated numerous local etiologic factors including; ectopic tooth development or eruption, thick mucosal or bony barrier, premature apical closure, unfavorable tooth rotation, altered eruption sequence, premature loss of a deciduous tooth, retained or ankylosed deciduous teeth, presence of supernumerary teeth, presence of a cyst, insufficient space in the dental arch, sequelae of oral trauma. ${ }^{5}$ In this report a supernumerary tooth was thought for responsible etiologic factors of mandibular incisors retention.

The supernumerary teeth (hyperdontio) is a state which can be defined as any teeth or tooth substance in excess of the usual configuration of the normal number of deciduous or permanent teeth. ${ }^{6}$ Although several theories have been submitted to explain their development, the precise etiology of supernumerary teeth is not clearly understood. ${ }^{7}$ But the common suggestion about etiology of supernumerary teeth is considered to develop as a result of horizontal proliferation or a hyperactivity of the dental lamina. ${ }^{8}$

The presence of supernumerary teeth may be part of many genetically determined syndromes and birth defect like cleidocranial dysostosis, cleft lips, cleft palate, Gardner's syndrome, and Down syndrome. And they may also accompany less frequently other syndrome including Marfan syndrome, Fabry Anderson's syndrome, Chondroectodermal dysplasia, Ehlers-Danlos syndrome, incontinentia pigmenti and Trico-Rhino-Phalangeal syndrome..$^{6,9-11}$ There were no skeletal abnormali-

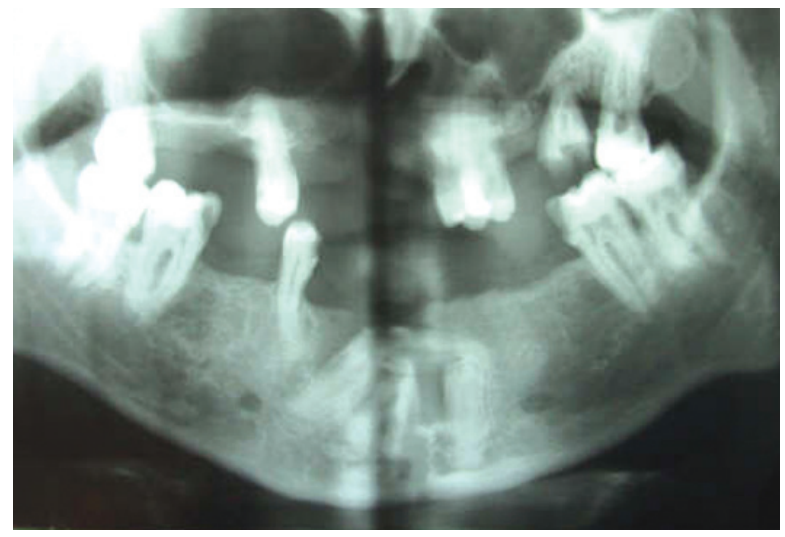

Figure 2. Panoramic radiograph showing impacted teeth in the anterior region of mandible. 
ties or birth defect associated with this case. The probable causal factors are supernumerary tooth and angulations of tooth germs.

The frequency of supernumerary tooth seeing in the mandibular incisor area is uncommon. A study was conducted in Australia demonstrated that supernumerary teeth were most frequently located in maxillary incisor region (64.3\%) with mesiodens accounting for $32.4 \%$ of such presentation. In decreasing order of frequency came supernumeraries in the maxillary third molar region (29.6\%), mandibular third molar region $(7.0 \%)$, mandibular premolar region $(7 \%)$, maxillary premolar region $(4.2 \%)$ and mandibular incisor region $(4.2 \%) .{ }^{10}$

Although supernumerary teeth could erupt normally, they generally remain impacted. It has been found that approximately $25 \%$ of permanent supernumerary teeth are erupted and remainders are unerupted. ${ }^{11}$ Supernumerary teeth can effect the normal position and eruption of adjacent teeth often requiring clinical intervention. ${ }^{12}$ The most common complication is failure of eruption of maxillary incisors. ${ }^{11}$ In this report supernumerary tooth is responsible for failure of eruption of mandibular incisors. The other probable complications of supernumerary teeth are; $;^{5,711,13}$ delays or impedes eruption of normal tooth, crowding, retained deciduous teeth, abnormal diastema, dilacerations, delayed or abnormal root development of permanent teeth, development of odontogenic cysts and fistulas, eruption into the nasal cavity, root resorption of adjacent teeth or mesiodens.

A recent study in Turkey was aimed to analyze the frequency and radiological feature of mesiodens in a group of children 123,000 pediatric patients) demonstrated that the main complica-

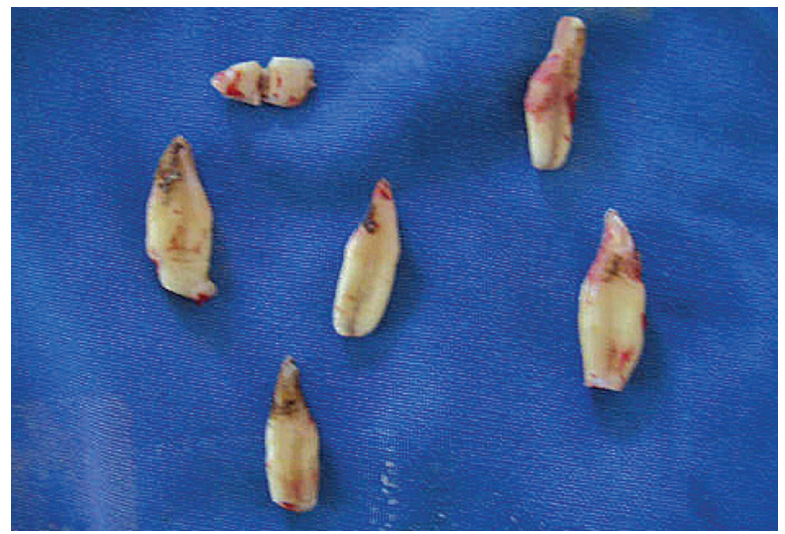

Figure 3. Normally formed cuspids and the square supernumerary tooth (on the left top). tions of supernumerary teeth were delayed eruption of the permanent incisors (38.8\%), maxillary midline diastema (17.6\%), axial rotation or inclination of erupted permanent incisors (16.4\%), and resorption of the adjacent teeth (4.7\%). ${ }^{14}$ Supernumerary tooth had impeded eruption of mandibular incisors and then caused formation of dentigerous cyst in our patient.

The treatment protocol of supernumerary teeth is differentiated. When supernumerary teeth are discovered a decision needs to be made whether to remove or monitor them. ${ }^{15}$ Supernumerary teeth can be monitored without removal if it is asymptomatic, does not hamper eruption of teeth, no active associated pathology. ${ }^{16}$ But if left, they may erupt and disrupt the occlusion. If these teeth remain impacted, not only may they disrupt occlusal development, but cystic lesions may develop around them as in our case. ${ }^{15}$ But, before surgical removal, localization and relation to the roots of primary teeth and erupted permanent, unerupted permanent teeth, floor of the nose, maxillary sinus and other structures must be assessed. ${ }^{16}$

Routine treatment for impacted teeth is their removal when patients have any symptoms of indications of pathological changes, or if removal is considered to be essential for orthodontic treatment. Removal should be carried out as soon as possible to avoid tooth malpositioning, diastemas, root resorption, bone resorption, and cystic degeneration. ${ }^{17,18}$ Assael ${ }^{17}$ reported that the contention that impacted teeth should be electively removed is in part based upon the significant risk of destructive pathology in follicular tissue. He also stated that the incidence of locally destructive or life threatening pathology associated with impacted teeth, such as squamous cell carcinoma increases with age, and early removal of impacted teeth is usually desirable and that the retention of impacted teeth requires lifelong monitoring for disease. Often no treatment is required for unerupted and asymptomatic impacted teeth that are embedded deeply in bone and do not cause any problem. Huang and Mercier ${ }^{19}$ reported that the removal of asymptomatic impacted teeth in denture-bearing areas or in areas undergoing prosthetic surgery is unnecessary as long as the integrity of the covering tissue is preserved.

Methods of management of crowding or impaction due to supernumerary are; remove super- 
numerary teeth or tooth only, remove supernumerary teeth and bone overlying impacted teeth, incision of fibrous tissue over the alveolar ridge to promote the eruption with or without orthodontic traction. ${ }^{3,16}$ Surgical exposures of impacted incisors or surgical repositioning have been used to bring impacted teeth into occlusion. ${ }^{20,21}$ The disadvantage of the combined surgical/orthodontic therapy is required a longer treatment period and some complication including ankylosis, non-vital pulps and root resorptions may be encountered. When an extensive amount of bone is removed or an open approach method is used to expose the impacted teeth, surgically, periodontal complication can be occurred such as gingival recession, delay in periodontal healing, gingivitis, bone loss and decrease in the width of keratinized gingiva. ${ }^{20}$ In this case we prefer extraction of all impacted teeth because of presence an associated cyst.

Alveolar ridge resorption is due to local factors such as mechanical forces associated with denture occlusal trauma and systemic factors; such as nutritional and hormonal imbalance and metabolic bone disease factors. ${ }^{22}$ In this case both inflammation and cystic degeneration accelerated bone resorption along with effect of wearing denture on bone resorption. Patient has been avoided to wear his older removable partial denture. Suitable prosthesis was made after hard and soft tissue healing had been obtained.

In this report, impacted mandibular anterior permanent incisors with supernumerary tooth in a healthy 39 year-old man was presented that did not correspond with any syndromes. Cystic degeneration caused by impaction of teeth could lead pathologic fracture of mandible. The patient showed uneventfully healing during 2 year followup.

\section{REFERENCES}

1. Peterson LJ, Ellis E III, Hupp JR, Tucker MR. Contemporary oral and maxillofacial surgery, 2nd edn. Mosby, St Louis,Mo., 1993

2. Rasmussen $P$, Hansen AS, Berg E. Inherited retarded eruption. J Dent Child 1983;50:268-273.

3. Regezi JA, Sciubba JJ, Jordan RCK. Oral Pathology: Clinical Pathologic Correlations.4th ed, Saunders, Elsevier Science. 2003;367-384

4. Alling CA, Hellric JF, Alling R. Impacted teeth, WB. Saunders. Co. 1993;46-49.
5. da Costa CT, Torriani DD, Torriani MA, da Silva RB. Central Incisor Impacted by an Odontoma. J Contemp Dent Prac 2008;9:1-7.

6. Pels E, Mielnik-Blaszczak M, Szyszkowska AM, Krawczyk D, Prucia G, Kulazyynska-kaminska E. Rare cases of supernumerary teeth. Ann Uni Mar Cur 2006;2:849-853.

7. Gomes CO, Drummond SN, Jham BC, Abdo EN, Mesquita RA. A survey of 460 supernumerary teeth in Brazilian children and adolescents. Int J Ped Dent 2008;18:98-106.

8. Kökten $G$, Balcıoḡlu H, Büyükerten M. Supernumerary fourth and fifth molars: a report of two cases. J Contemp Dent Pract 2003;4:67-76.

9. Ramsaran AS, Barclay S, Scipio E, Ogunsalu C. Non-syndromal multiple buried supernumerary teeth. West Indian Med $J$ 2005;54:334-336.

10. Scheiner MA, Sampson WJ. Supernumerary teeth. A review of the literature and four case reports. Aust Dent $J$ 1997;42:160-165.

11. Rajab LD, Hamdan MAM. Supernumerary teeth: review of the literature and a survey of 152 cases. Int J Ped Dent 2002;12:244-254.

12. Harris EF, Clark LL. An epidemiological study of hyperdontia in American blacks and whites. Angle Orthod 2008;78:460-465.

13. Solares R, Romero MI. Supernumerary premolars: a literature review. Ped Dent 2004;26:450-458.

14. Gündüz K, Celenk P, Zengin Z, Sümer P. Mesiodens: a radiographic study in children. J Oral Sci 2008;50:287-291.

15. Cochrane SM, Clark JR, Hunt NP. Late developing supernumerary teeth in the mandible. Br J Orthod 1997;24:293296.

16. Bhat M. Supplemental mandibular incisor. J Indian Soc Pedod Prev Dent 2006; special issue:20-23

17. Assael LA. Impacted Teeth: Reflections on Curran, Kugelberg, and Rood. J Oral Maxillofac Surg 2002;60:611-612.

18. Ashkenazi M, Greenberg BP, Chodik G, Rakocz M. Postoperative prognosis of unerupted teeth after removal of supernumerary teeth or odontomas. Am J Orthod Dentofac Orthop 2007;131:614-619.

19. Huang $H$, Mercier P. Asymptomatic impacted teeth in edentulous jaws undergoing preprosthetic surgery. A longterm evaluation. Int J Oral Maxillofac Surg 1992;21:147-149.

20. Kocadereli I, Turgut MD. Surgical and orthodontic treatment of an impacted permanent incisor: case report. Dent Trauma 2005;21:234-239.

21. Kamakura S, Matsui K, Katau F, Shirai N, Kochi S, Motegi K. Surgical and orthodontic management of compound odontoma without removal of the impacted permanent tooth. Oral Surg Oral Med Oral Pathol Oral Radiol Endod 2002;4:540-542. 
$\square$ Impacted mandibular permanent incisors

22. Devlin H, Ferguson MWJ. Alveolar ridge resorption and mandibular atrophy. A review of the role of local and systemic factors. Br Dent $J 1991 ; 170: 101-104$ 